\title{
Avaliação dos impactos do processo de desertificação no Seridó Ocidental a partir de indicadores biofísicos e sociais
}

\author{
Assessment of the impacts of the desertification process in the Western Seridó by biophysical and \\ social indicators
}

Evaluación de los impactos del proceso de desertificación en el Seridó Occidental mediante indicadores biofísicos y sociales

\begin{abstract}
Resumo
O processo de degradação das terras do semiárido está associado às vulnerabilidades ambientais e econômicas relacionadas a fatores de origem natural e principalmente antrópico. Historicamente a microrregião do Seridó Ocidental Paraibano teve a Caatinga como meio de subsistência e fonte de renda. A retirada abusiva da cobertura vegetal está ligada à presença de atividades econômicas exploratórias, como a agricultura, pecuária, cotonicultura e desde então a mineração. Estudos iniciados desde a década de 80 por Vasconcelos Sobrinho já apontava a microrregião como uma área de elevado risco de desertificação, posteriormente chamado de Núcleo de Desertificação devido às características naturais e as consequências de atividades antrópicas que devastam grandes espaços para pastagem retirando lenha e carvão para consumo próprio, assim como para olarias, panificadoras e outras finalidades econômicas energéticas. Esse trabalho faz o levantamento das características naturais (precipitação, clima, solo e relevo bem como da retirada da lenha e madeira para abastecimento local e de outras localidades) que favorecem a degradação ambiental e os processos que levam à desertificação.
\end{abstract}

Palavra-chave: Desmatamento; Extração vegetal; Seridó Ocidental Paraibano.

\begin{abstract}
The process of degradation of semi-arid lands is associated with environmental and economic vulnerabilities related to factors of natural and mainly anthropic origin. Historically, the micro-region of Seridó Ocidental Paraibano had the Caatinga as a means of subsistence and source of income. The abusive removal of vegetation cover is linked to the presence of exploratory economic activities, such as agriculture, livestock, cotton farming and since then mining. Studies initiated in the 1980s by Vasconcelos Sobrinho already pointed to the micro-region as an area of high risk of desertification, later called the Desertification Nucleus due to the natural characteristics and consequences of human activities that devastate large spaces for pasture, removing firewood and charcoal to consumption, as well as for potteries, bakeries and other energy-saving purposes. This work surveys the natural characteristics (rainfall, climate, soil and relief, as well as the removal of firewood and wood for local supply and other locations) that favor environmental degradation and the processes that lead to desertification.
\end{abstract}

Keywords: Deforestation; Plant extraction; Seridó Ocidental Paraibano.

\section{Resumen}

El proceso de degradación de las tierras semiáridas está asociado a vulnerabilidades ambientales y económicas relacionadas con factores de origen natural y principalmente antrópico. Históricamente, la microrregión de Seridó Ocidental Paraibano tuvo a la Caatinga como medio de subsistencia y fuente de ingresos. La remoción abusiva de la cobertura vegetal está ligada a la presencia de actividades económicas exploratorias, como la agricultura, la ganadería, el cultivo del algodón y desde entonces la minería. Estudios iniciados en la década de 1980 por Vasconcelos Sobrinho ya apuntaban a la microrregión como área de alto riesgo de desertificación, luego denominada Núcleo de Desertificación debido a las características naturales y consecuencias de las actividades humanas que arrasan grandes espacios para pastos, extrayendo leña. y carbón al consumo, así como para alfarerías, panaderías y otros fines de ahorro de energía. Este trabajo releva las características naturales (lluvia, clima, suelo y relieve, así como la extracción de leña y madera 
para el abastecimiento local y otros lugares) que favorecen la degradación ambiental y los procesos que conducen a la desertificación.

Palabras clave: Deforestación; Extracción vegetal; Seridó Ocidental Paraibano.

\section{Introdução}

A degradação do meio ambiente tem afetado o dia a dia de grande parte da população mundial, comprometendo a produtividade da agricultura, produção biológica, pastagens e áreas de vegetação nativa. As atividades antrópicas são responsáveis pela transformação do meio ambiente e pelo consumo acentuado dos recursos naturais existentes. É imprescindível combater os efeitos mitigantes causados pela degradação ambiental e assegurar um modelo de crescimento econômico sustentável.

Desde a década de 1960 várias conferências vêm sendo realizadas no mundo na tentativa de estabelecer estudos sobre degradação ambiental. O Brasil realizou a Eco-92 na cidade do Rio de Janeiro onde foram consolidados vários documentos oficiais, entre eles a Carta da Terra, a Declaração de Princípios sobre Florestas e a Agenda 21, no qual a comunidade científica definiu o conceito de desertificação como sendo a degradação da terra nas zonas áridas, semiáridas e subúmidas resultantes de vários fatores, incluindo variações climáticas e atividades humanas (Nações Unidas, 1997).

O semiárido nordestino apresenta várias características que o torna vulnerável a processos de desertificação, os quais já são notados em grande parte de sua área. Segundo estudos pioneiros de Vasconcelos Sobrinho, (1971) sobre processos de degradação em espaços semiáridos, foram identificadas várias áreas em elevado risco de desertificação e posteriormente definidas como núcleos de desertificação.

O Seridó Ocidental da Paraíba apresenta agressivos processos de degradação e a principal causa é a substituição da área vegetal nativa e do solo por agricultura, pecuária, extração da madeira para lenha e pelas atividades mineradoras. Dessa forma essa microrregião é considerada uma área susceptível a desertificação (ASD’s), apresentando longos períodos sem chuvas que provocam prejuízos a comunidade (MMA, 2004).

Fatores como variações climáticas e atividades antrópicas desenfreadas contribuem para o aceleramento dos processos erosivos e criam condições para potencializar os efeitos negativos. De acordo com levantamento de dados do Centro de Sensoriamento Remoto do Instituto Brasileiro do Meio Ambiente e dos Recursos Naturais Renováveis (IBAMA), foram suprimidos 494 km² de vegetação da Caatinga nos anos de 2010-2011, uma queda de 56\% em relação ao período anterior 20092010 MMA, (2017). Porém, o desmatamento continua ocorrendo de forma acelerada nos últimos anos, principalmente pelo consumo ilegal dos recursos naturais para alimentar a indústrias e uso doméstico.

Para o proposto estudo, foram levados em consideração os problemas ocasionados pelas atividades econômicas exploratórias, associados a fatores físicos e climáticos, que exercem grande influência nos processos geradores de degradação ambiental. A microrregião do Seridó Ocidental da paraíba, por sofrer intensa influência de fatores antrópicos e naturais, é considerado um núcleo de desertificação. Conseguinte, a importância do uso racional dos recursos naturais, como no caso do Seridó Ocidental paraibano, determinou a base para pesquisa sobre a temática. Dessa forma, a pesquisa propõe-se a analisar o processo de desertificação ocorrido na região do Seridó Ocidental paraibano através de indicadores biofísicos e sociais.

\section{Metodologia}

\subsection{Caracterização da Área}

A microrregião do Seridó Ocidental Paraibano é composta por seis municípios e está localizada na região centro-norte da Mesorregião da Borborema (Figura 1). Pertence ao bioma Caatinga tornando-se vulnerável à degradação das terras devido ao déficit pluviométrico e por práticas inadequadas de extração vegetal e manejo do solo. Segundo dados do censo do Instituto Brasileiro de Geografia e Estatística, (IBGE), a população era de 39.122 habitantes no ano de 2010. 
Figura 1: Mapa de Localização do Seridó Ocidental.

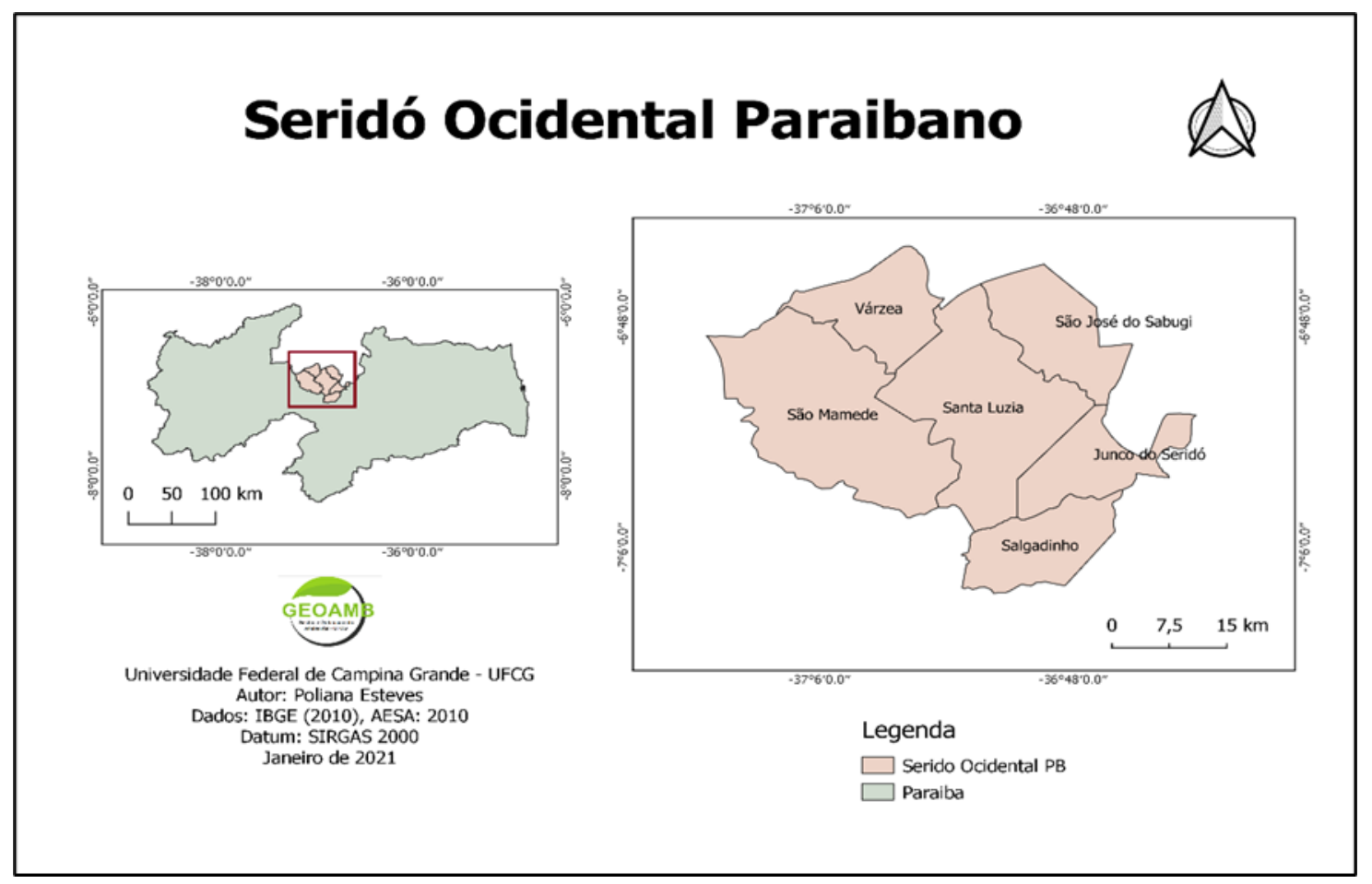

Fonte: Autores (2021).

Por possuir distribuição e quantidade das chuvas irregulares e concentradas durante o ano, o Seridó Ocidental paraibano é uma das localidades mais secas do semiárido nordestino, com precipitações pluviométricas médias anuais muito baixas, e uma longa estação seca (NIMER, 1972).

Segundo dados da AESA, a época chuvosa ocorre em apenas dois ou três meses do ano, e mesmo assim em pequenas quantidades, iniciando entre fevereiro e março e perdurando até os meses de abril e maio.

Para Barros et al., (2012), a classificação climática de Köppen-Geiger, baseada na quantidade média de precipitação e temperatura, ainda é o método mais utilizado na caracterização do clima de uma determinada área ou região (Figura 2).

Dados da SUDENE mostram que a pluviometria média do Seridó Ocidental paraibano possui médias anuais de 569 mm e temperaturas anuais variando entre 16 e $25^{\circ} \mathrm{C}$, com máxima de $33^{\circ} \mathrm{C}$. 
Figura 2: Tipos de clima do Estado da Paraíba, segundo a classificação de Köppen.

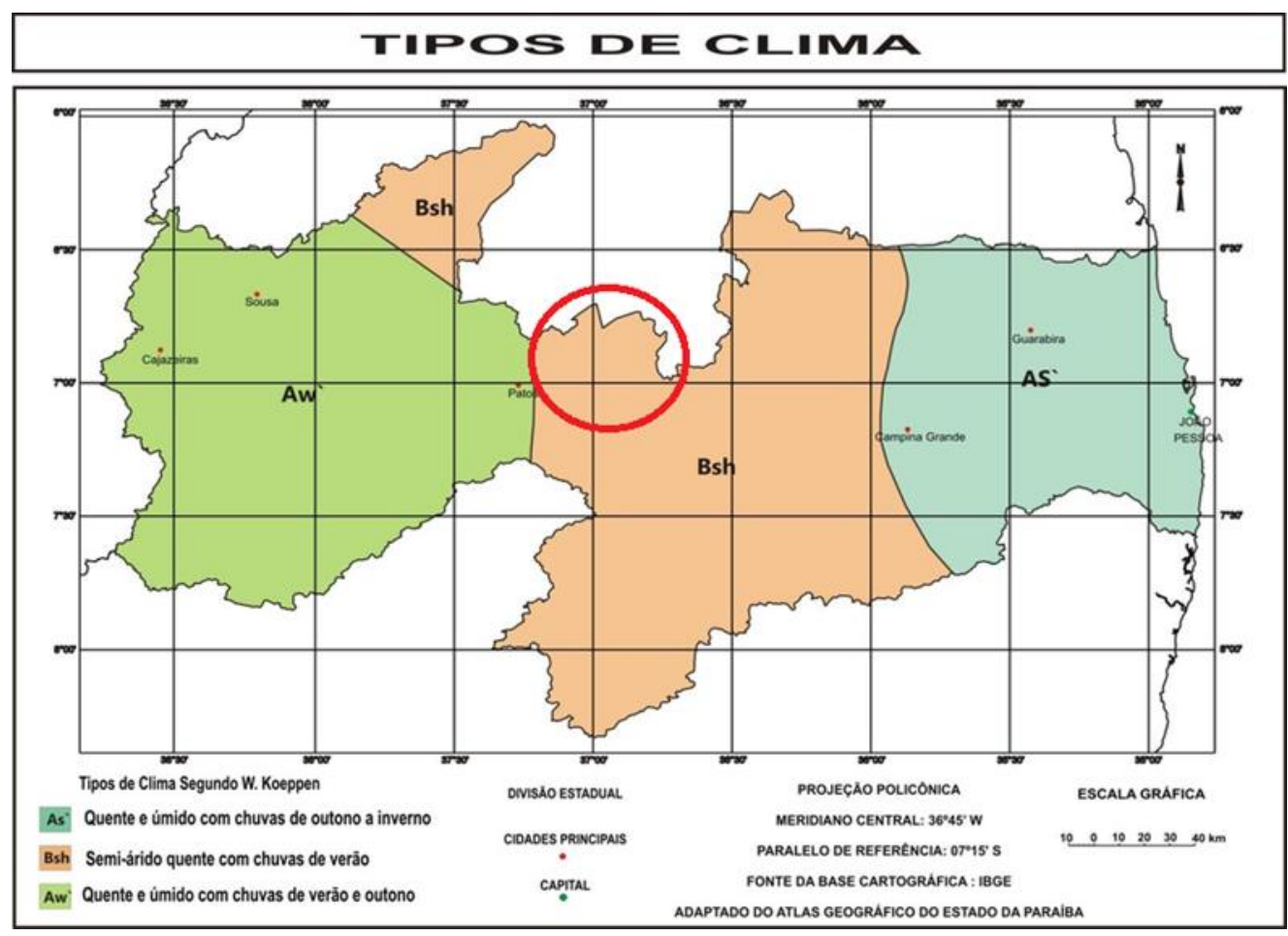

Fonte: Atlas geográfico do Estado da Paraíba (2017).

O Seridó Ocidental da Paraíba é uma região semiárida inserida no Bioma da Caatinga, possui vegetação de Caatinga Arbórea com ocorrência de caatinga hiperxerófila arbustiva aberta, de acordo com a maior ou menor disponibilidade hídrica. Nestas áreas, a caatinga apresenta-se com predomínio de porte arbustivo, com densidade variável e na maioria das vezes rica em cactáceas e bromeliáceas (Jacomine, 1972).

A geologia é variável, porém predomina o embasamento cristalino seguido de áreas sedimentares em menor fração. O solo é raso, pedregoso e com cobertura pouco espessa, com alta susceptibilidade erosiva (Jacomine, 1996). Predomina na região os solos Neossolo Litólico e o Luvissolo Crômico com baixa fertilidade. O relevo é suave e moderadamente ondulado com limitações hídricas. Faz parte da bacia hidrográfica do rio Piranhas, sendo essa a principal bacia da microrregião.

O desmatamento acentuado nessa microrregião tem ocasionado um solo desprotegido e susceptível a erosões provenientes das chuvas torrenciais e do impacto do escoamento superficial (Sales et al., 2006). Essa degradação faz com que haja diminuição da fertilidade do solo e impossibilita o surgimento de novas espécies.

Para a população rural pobre do semiárido, o desmatamento desenfreado da madeira para diversos usos (consumo doméstico, cozimento de tijolos em cerâmicas, produção de carvão, construção de cercas, galinheiros e cercados para animais) faz com que a utilização dos recursos seja uma fonte de renda e de subsistência das famílias (Guerra \& Cunha, 1996).

\subsection{Materiais e Métodos}

A pesquisa apresenta caráter exploratório e descritivo do período compreendido entre os anos de 2008 e 2018 das atividades econômicas exploratórias na microrregião do Seridó Ocidental paraibano que aceleram a degradação do ambiente. A metodologia utilizada para a pesquisa partiu de levantamento de dados obtidos em sites oficiais, através de órgãos públicos como CIDADES.IBGE, IBAMA, CENSO AGROPECUÁRIO, EMATER entre outros sites na internet. Também foi utilizado revisão bibliográfica com propósito de expandir o entendimento sobre as teorias propostas.

Para fundamentar os resultados, foi de fundamental importância conhecer dados climáticos de precipitação, secas e eventos extremos compreendidos entre o período estipulado para a pesquisa. Os dados foram concedidos pela Agência Executiva 
das Águas da Paraíba (AESA) e relacionados com as informações encontrados na pesquisa para tentar compreender a correlação existente entre a extração desse recurso natural e a demanda existente sobre as atividades econômicas exercidas na microrregião.

Para a análise da cobertura vegetal serão utilizadas imagens de satélite a partir da aplicação do índice de realce da vegetação conhecido como NDVI, como base imagens do satélite Landsat 8. O uso de Geotecnologias e técnicas de Sensoriamento Remoto permitirá diagnosticar o grau de degradação das terras, sendo uma prática eficiente nos estudos da desertificação.

O uso de plataformas de planilhas, gráficos e cálculos, EXCEL, assim como software direcionado às informações geográficas, Qgis, permitiram adicionar e tratar as informações disponíveis organizando-as de forma a facilitar a análise dos dados.

\section{Resultados e Discussão}

O estudo mostra que a população do Seridó Ocidental teve como modelo de sua economia atividades ligadas à pecuária e lavouras, posteriormente substituídas pela cotonicultura até os anos 70. Essas ocupações foram responsáveis por muitos anos pelo estabelecimento das famílias na zona rural, cuja atividade gerou possibilidades de ocupação e emprego. No entanto a pressão antrópica relacionada ao uso inadequado dos recursos naturais, pastoreio e a mineração resultaram em elevado custo ambiental (PNDR, 2012). Por apresentar uma cultura de fácil adaptação às condições áridas da microrregião, o algodão se expandiu facilmente substituindo as atividades pecuárias e fixando-se como importante fonte de economia no século XIX (MEDEIROS, 1980). A crise algodoeira levou ao desmatamento da vegetação nativa para abastecer as olarias e panificadoras, tanto locais quanto de outros estados, comprometendo a biodiversidade e a degradação do solo (Pereira et al., 2002).

A mineração é atualmente a atividade econômica que exerce relevante importância em boa parte da população da área. De acordo com Freitas (2013), nos anos 1980 o Seridó Ocidental Paraibano passou por períodos de transição econômica - crise pecuária, do algodão - fazendo com que houvesse um processo de reestruturação econômica. O comércio e a mineração têm se consolidado como a atividade de maior potencial econômico dos municípios, porém essa atividade está voltada, particularmente, para o comércio externo, não gerando melhores condições de vida para a população da microrregião.

Segundo o IBGE (2010), os municípios não são populosos, destacando-se Santa Luzia e Junco do Seridó. A população maioritariamente vive na área urbana, com exceção do município de Salgadinho, onde o percentual de população rural representa 91,6\% a mais do que a população residente na área urbana (Gráfico 1). 
Gráfico 1: População Urbana e Rural dos municípios do Seridó Ocidental Paraibano.

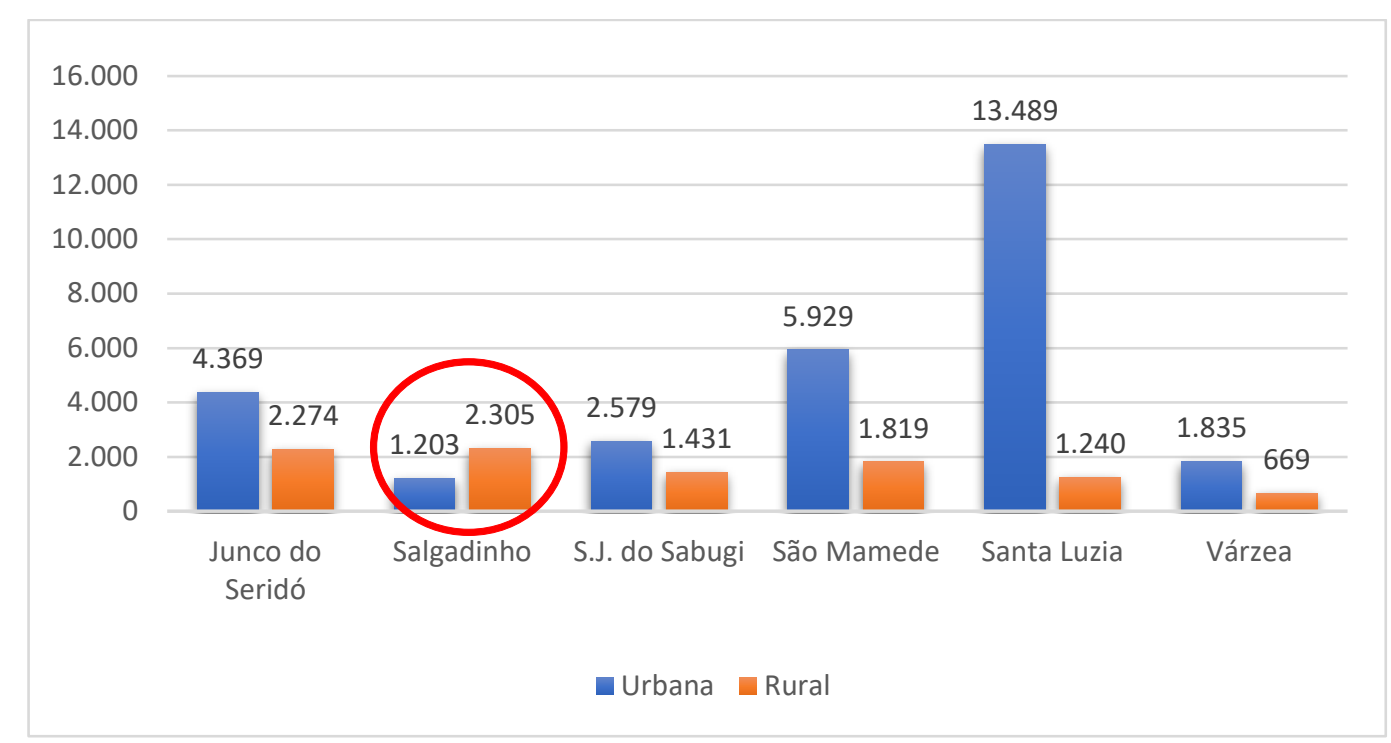

Fonte: IBGE (2010).

Embora a maioria da população resida na área urbana, dados do IBGE apontam que parte das famílias, mesmo residindo nas cidades, mantém atividades ligadas ao setor rural, principalmente agropecuária IBGE (2010). A faixa etária da população da área mostra heterogeneidade em relação a distribuição de jovens, adultos e idosos (Quadro 1). Observa-se que no município de Santa Luzia a população adulta destaca-se em relação à jovens e adultos. Salgadinho apresenta baixa população de idosos, todavia a quantidade de adultos e jovens é aproximada.

Quadro 1: Distribuição etária da população do Seridó Ocidental da Paraíba.

\begin{tabular}{|l|r|r|r|}
\hline \multicolumn{1}{|c|}{ Municípios } & \multicolumn{1}{c|}{$\begin{array}{c}\text { População } \\
\text { (0 a 19 anos) }\end{array}$} & $\begin{array}{c}\text { População } \\
\text { (20 a 59 anos) }\end{array}$ & $\begin{array}{c}\text { População } \\
\text { (60 anos ou mais) }\end{array}$ \\
\hline Junco do Seridó & 2.425 & 3.439 & 779 \\
\hline Salgadinho & $\mathbf{1 . 3 4 6}$ & $\mathbf{1 . 7 1 5}$ & 547 \\
\hline São J. do Sabugi & 1.323 & 2.161 & 1.323 \\
\hline São Mamede & 2.367 & 4.055 & 2.125 \\
\hline Santa Luzia & 4.896 & $\mathbf{7 . 6 9 8}$ & 424 \\
\hline Várzea & 741 & 1.335 & \\
\hline
\end{tabular}

Fonte: IBGE (2010).

A força de trabalho da população se dá por uma maior concentração de pessoas em idade adulta, cuja faixa etária é a mais ativa economicamente. No Seridó Ocidental Paraibano o número pessoas adultas compreende a maior parte da população, em contrapartida a quantidade de idosos é bem menor que a de jovens (Gráfico 2). Esse fato demonstra que a expectativa de vida nesta microrregião é baixa em virtude de fatores relacionados à situação econômica e a qualidade de vida abaixo da média. 
Gráfico 2: Distribuição populacional do Seridó Ocidental Paraibano.

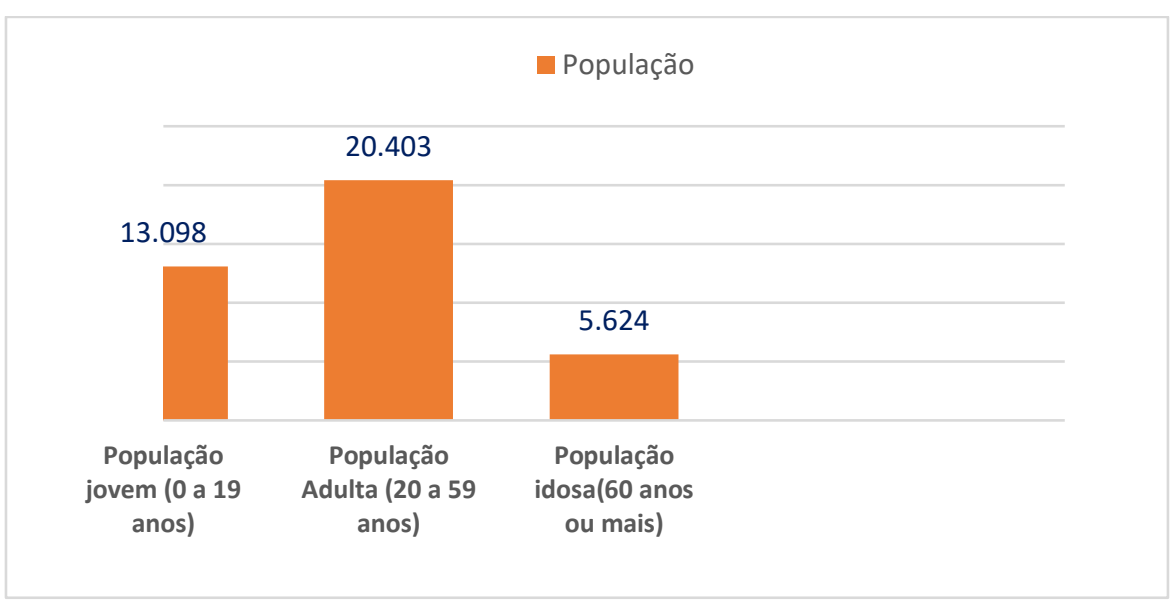

Fonte: IBGE (2010).

\subsection{Tipos de Documento}

Ao delimitar a pesquisa por "tipos de documentos", apresentados na (Figura 1), foram recuperados trabalhos que continham registros da palavra-chave inserida nos campos da pesquisa. Foram identificados 193 trabalhos, sendo a maioria articles (193), proceedings paper (10), editorial material (08), review (06), correction (03), book review (02) e early access (01).

É característica da microrregião do Seridó Ocidental paraibano as altas temperaturas, chuvas intervaladas, assim como curto período pluvial. Essa particularidade da região pode agravar a degradação das terras e consolidar a prática de atividades econômicas predatórias e de queima da cobertura vegetal.

Dados da EMATER, (2021) mostram que a distribuição de chuvas no Seridó Ocidental é irregular e de acordo com a Tabela 2 percebe-se que a máxima pluvial ocorre entre os meses de fevereiro a abril podendo se estender até o mês de maio. Destaca-se nesse sentido os municípios de São Mamede e Várzea com os maiores índices ocorridos.

Tabela 2: Dados pluviométricos Seridó Ocidental paraibano.

\begin{tabular}{|c|c|c|c|c|c|c|c|c|c|c|c|c|c|}
\hline Localidade & Jan & Fev & Mar & Abr & Mai & Jun & Jul & Ago & Set & Out & Nov & Dez & Total \\
\hline $\begin{array}{c}\text { Junco do } \\
\text { Seridó }\end{array}$ & 83,0 & 66,2 & 132,4 & 99,4 & 66,8 & 52,2 & 24,2 & 15,6 & 5,9 & 4,2 & 5,5 & 21,3 & $\mathbf{5 7 6 , 7}$ \\
\hline Salgadinho & 46,2 & 68,1 & 120,6 & 102,4 & 56,6 & 25,2 & 17,6 & 7,7 & 2,1 & 2,5 & 5,9 & 16,1 & $\mathbf{4 7 1}$ \\
\hline Santa Luzia & 49,9 & 97,8 & 153,0 & 128,9 & 48,2 & 16,5 & 8,6 & 2,5 & $\mathbf{1 , 8}$ & 3,8 & 7,6 & 22,4 & $\mathbf{5 4 1}$ \\
\hline $\begin{array}{c}\text { S. José } \\
\text { Sabugi }\end{array}$ & 85,6 & 124,5 & 184,0 & 155,9 & 79,4 & 39,9 & 27,2 & 11,4 & 7,0 & 8,9 & 14,2 & 32,6 & $\mathbf{7 7 0 , 6}$ \\
\hline São Mamede & 70,8 & 126,8 & $\mathbf{1 9 0 , 9}$ & 171,3 & 67,6 & 28,3 & 14,6 & 3,0 & 2,4 & 5,3 & 4,6 & 25,6 & $\mathbf{7 1 1 , 2}$ \\
\hline Várzea & 52,0 & 118,1 & $\mathbf{1 8 8 , 6}$ & 164,2 & 58,0 & 22,6 & 12,5 & 2,0 & $\mathbf{1 , 0}$ & 2,9 & 6,6 & 25,2 & $\mathbf{6 5 3 , 7}$ \\
\hline Média & $\mathbf{6 4 , 6}$ & $\mathbf{1 0 0 , 3}$ & $\mathbf{1 6 1 , 6}$ & $\mathbf{1 3 7 , 0}$ & $\mathbf{6 2 , 8}$ & $\mathbf{3 0 , 8}$ & $\mathbf{1 7 , 5}$ & $\mathbf{7 , 0}$ & $\mathbf{3 , 4}$ & $\mathbf{4 , 6}$ & $\mathbf{7 , 4}$ & $\mathbf{2 3 , 9}$ & -- \\
\hline
\end{tabular}

Fonte: www.portal.insa.gov.br (2021)

O período mais seco acontece nos últimos meses do ano, entre agosto e novembro, podendo-se observar que o município de Santa Luzia e de Várzea atingiram os menores índices pluviométricos entre o período estudado (Gráfico 4).

Tais dados constatam que as condições climáticas podem ocasionar agravamento na degradação das terras na microrregião devido aos baixos índices pluviométricos, principalmente associado aos solos cristalinos e de pouca permeabilidade. 
Gráfico 4: Pluviosidade Mensal Seridó Ocidental - PB.

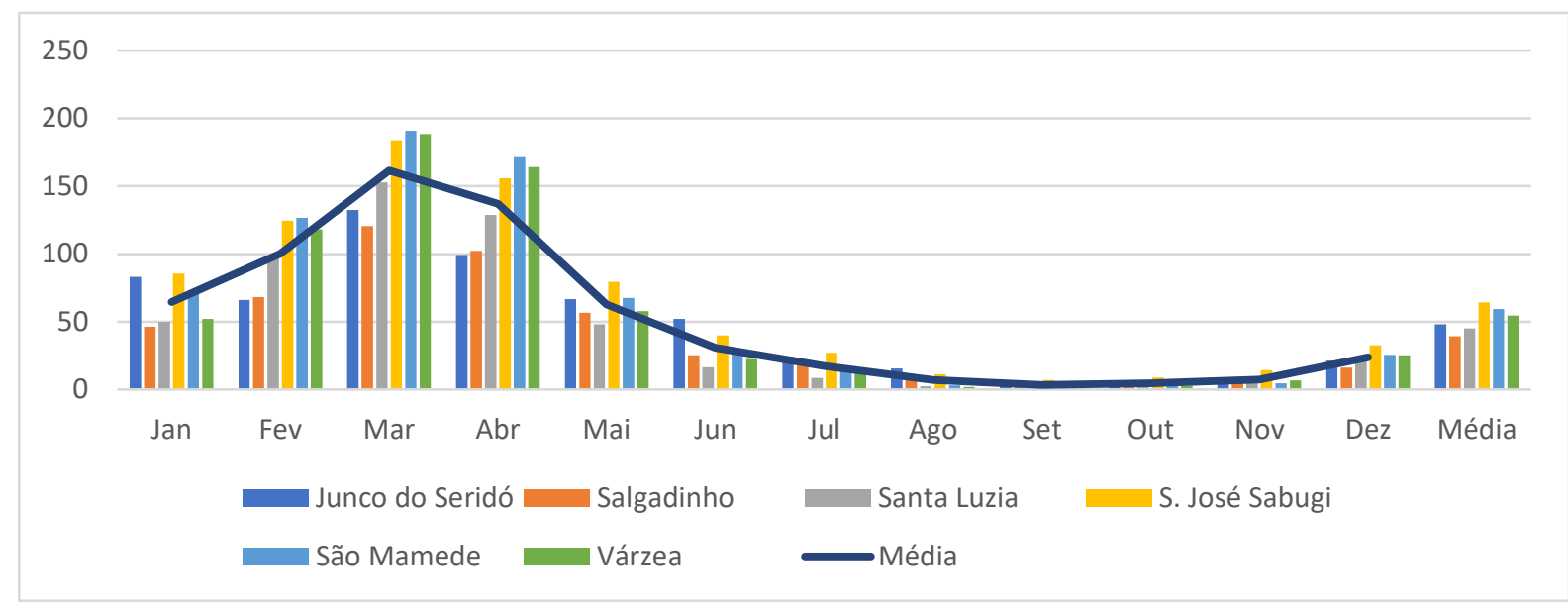

Fonte: $\underline{\text { http://www.aesa.pb.gov.br (2021) }}$

Durante o período chuvoso as cheias são violentas e torrenciais, e à medida que a estação seca vai se consolidando, os rios vão se esgotando gradativamente até secarem por completo. A série histórica da (Tabela 3 e do Gráfico 5) mostra que a média do ano mais chuvoso ocorreu em 2008 e que os anos mais secos se deram em 2012 e 2013.

Tabela 3: Série histórica pluviosidade anual Seridó Ocidental paraibano.

\begin{tabular}{|r|r|r|r|r|r|r|}
\cline { 2 - 7 } \multicolumn{1}{c|}{} & $\begin{array}{c}\text { Junco do } \\
\text { Seridó }\end{array}$ & \multicolumn{1}{c|}{ Salgadinho } & $\begin{array}{c}\text { Santa } \\
\text { Luzia }\end{array}$ & $\begin{array}{c}\text { S.J. de } \\
\text { Sabugi }\end{array}$ & $\begin{array}{c}\text { São } \\
\text { Mamede }\end{array}$ & Várzea \\
\hline $\mathbf{2 0 0 8}$ & $\mathbf{8 4 0 , 1}$ & $\mathbf{9 6 2 , 0}$ & $\mathbf{8 8 5 , 1}$ & $\mathbf{1 1 0 4 , 8}$ & $\mathbf{1 0 5 6 , 4}$ & $\mathbf{1 0 8 4 , 2}$ \\
\hline $\mathbf{2 0 0 9}$ & 1085,4 & 807,4 & 885,8 & 897,8 & 943,9 & 883,2 \\
\hline $\mathbf{2 0 1 0}$ & 644,1 & 620,0 & 546,4 & 619,6 & 581,9 & 550,5 \\
\hline $\mathbf{2 0 1 1}$ & 776,4 & 772,3 & 674,8 & 913,2 & 768,0 & 952,8 \\
\hline $\mathbf{2 0 1 2}$ & $\mathbf{1 3 9 , 2}$ & $\mathbf{9 0 , 8}$ & $\mathbf{1 9 0 , 8}$ & $\mathbf{1 5 8 , 5}$ & $\mathbf{3 6 7 , 5}$ & $\mathbf{1 3 8 , 0}$ \\
\hline $\mathbf{2 0 1 3}$ & $\mathbf{2 6 5 , 4}$ & $\mathbf{2 1 5 , 9}$ & $\mathbf{2 5 3 , 5}$ & $\mathbf{1 6 6 , 1}$ & $\mathbf{3 1 4 , 0}$ & $\mathbf{2 6 7 , 0}$ \\
\hline $\mathbf{2 0 1 4}$ & 480,4 & 287,2 & 384,9 & 364,5 & 784,6 & 384,7 \\
\hline $\mathbf{2 0 1 5}$ & 289,4 & 413,1 & 425,2 & 441,7 & 386,5 & 289,4 \\
\hline $\mathbf{2 0 1 6}$ & 421,6 & 266,3 & 404,1 & 498,3 & 566,7 & 537,0 \\
\hline $\mathbf{2 0 1 7}$ & 229,2 & 294,8 & 373,2 & 332,4 & 492,2 & 461,3 \\
\hline $\mathbf{2 0 1 8}$ & $\mathbf{6 4 4 , 7}$ & $\mathbf{5 7 3 , 8}$ & $\mathbf{5 7 3 , 8}$ & $\mathbf{7 1 2 , 4}$ & $\mathbf{7 1 5 , 6}$ & $\mathbf{5 4 7 , 5}$ \\
\hline Média & $\mathbf{5 2 8 , 7}$ & $\mathbf{4 8 2 , 1}$ & $\mathbf{5 0 8 , 8}$ & $\mathbf{5 6 4 , 4}$ & $\mathbf{6 3 4 , 3}$ & $\mathbf{5 5 4 , 1}$ \\
\hline
\end{tabular}

Fonte: http://www.aesa.pb.gov.br (2021)

A variabilidade temporal entre o período mais chuvoso e o mais seco é evidenciada observando a série histórica detalhada na (Tabela 2). Nota-se que houve distribuição gradual do ano mais úmidos e do mais seco. Verifica-se que após um ano bastante chuvoso - 2008 - ocorreram alguns anos de pluviosidade amena, vindo a diminuir em 2012 e 2013 , quando atingiram os menores índices. Após esses anos de pouca precipitação, a distribuição pluviométrica os índices voltaram a subir gradativamente até atingir um maior nível em 2018. 
Gráfico 5: Média Pluviométrica anual do Seridó Ocidental - 2008-2018.

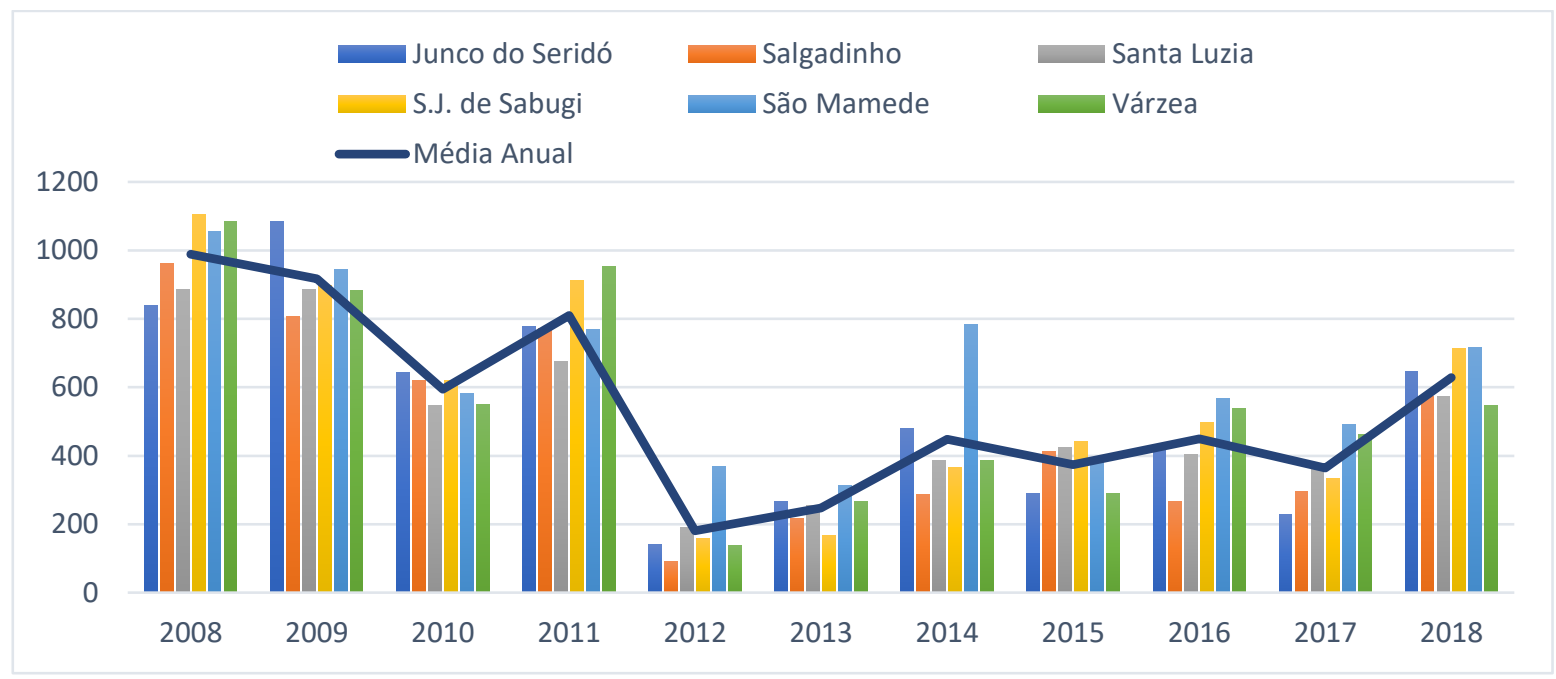

Fonte: http://www.aesa.pb.gov.br

Consoante os dados obtidos nos (Gráficos 6 e 7) do site do IBGE sobre a produção vegetal de carvão e lenha entre nos anos de 2008 e 2018, verifica-se que a microrregião do Seridó Ocidental passou por períodos específicos. No município de Salgadinho observa-se decréscimo na produção de carvão em relação aos outros municípios estudados, embora possua maior população residindo na área rural.

Gráfico 6: Extração de Carvão Seridó Ocidental - 2008 a 2018.

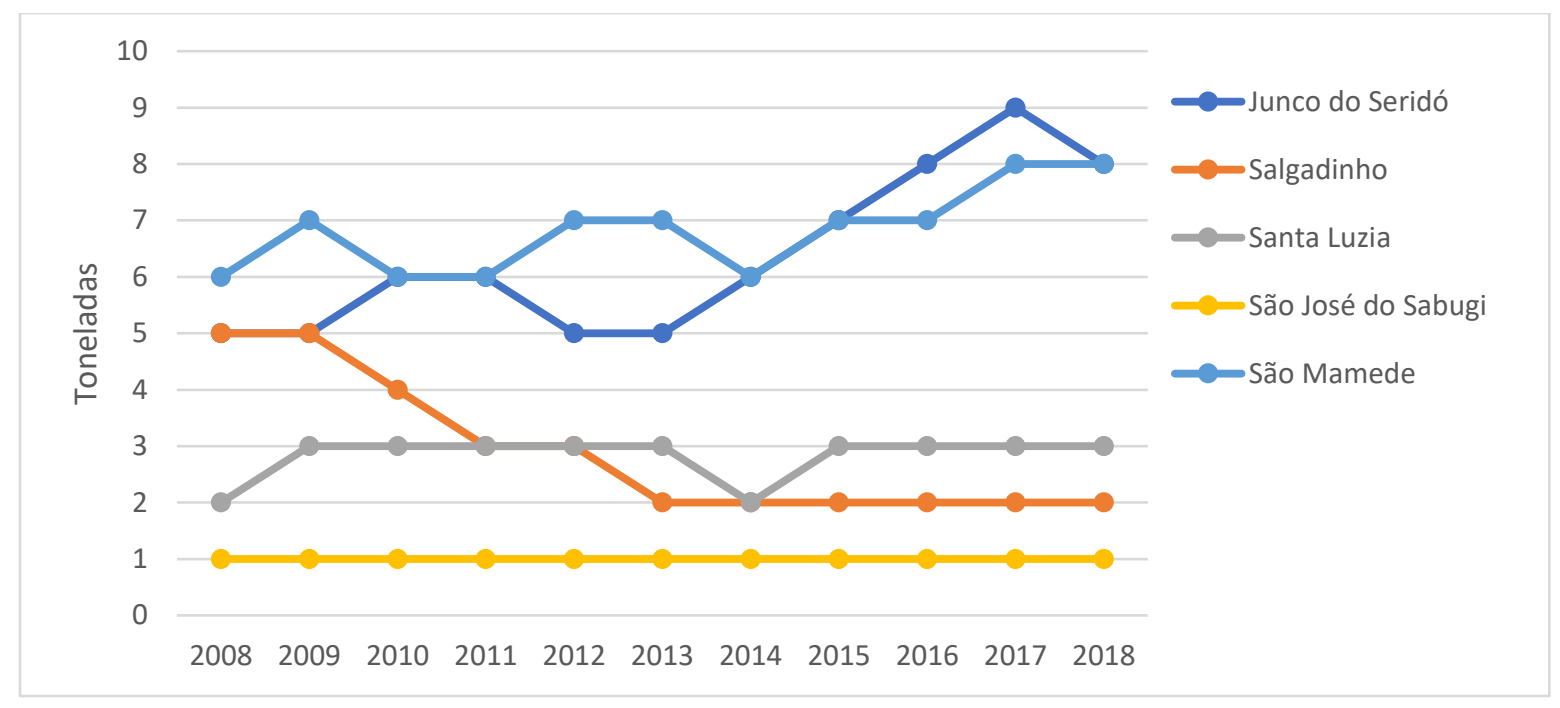

Fonte: IBGE (2021).

Em relação à extração de lenha, nota-se acréscimo em quase todos os municípios, com ligeira queda no ano de 2012 e 2015. Novamente verifica-se que a tendência mostrada no gráfico aponta diminuição tênue no município de Salgadinho nos últimos três anos da pesquisa. 
Research, Society and Development, v. 11, n. 3, e1411326082, 2022

(CC BY 4.0) | ISSN 2525-3409 | DOI: http://dx.doi.org/10.33448/rsd-v11i3.26082

Gráfico 7: Extração de Lenha Seridó Ocidental - 2008 a 2018.

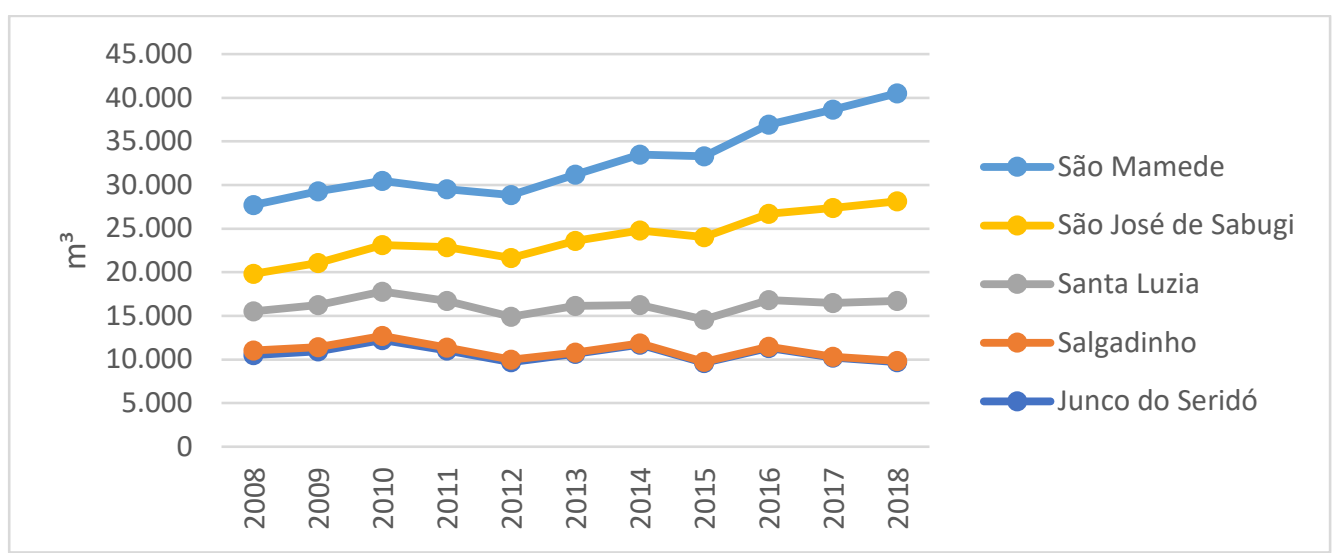

Fonte: IBGE (2021)

Devido aos fatores predatórios que a vegetação da caatinga vem sofrendo desde a ocupação da área ao longo dos anos observa-se que a vegetação vem diminuindo expressivamente. O uso da vegetação para extração de lenha e carvão vegetal e para a expansão agropecuária na região do Seridó Ocidental Paraibano vem deixando o solo desnudo e a vegetação rala, como mostram as séries de imagens em NDVI obtidas em 3 (três) anos diferentes: 2008, 2009 e mais atualmente em 2020 (Figura 3).

Figura 3: NDVI da área de estudo - 2008, 2009 e 2020.

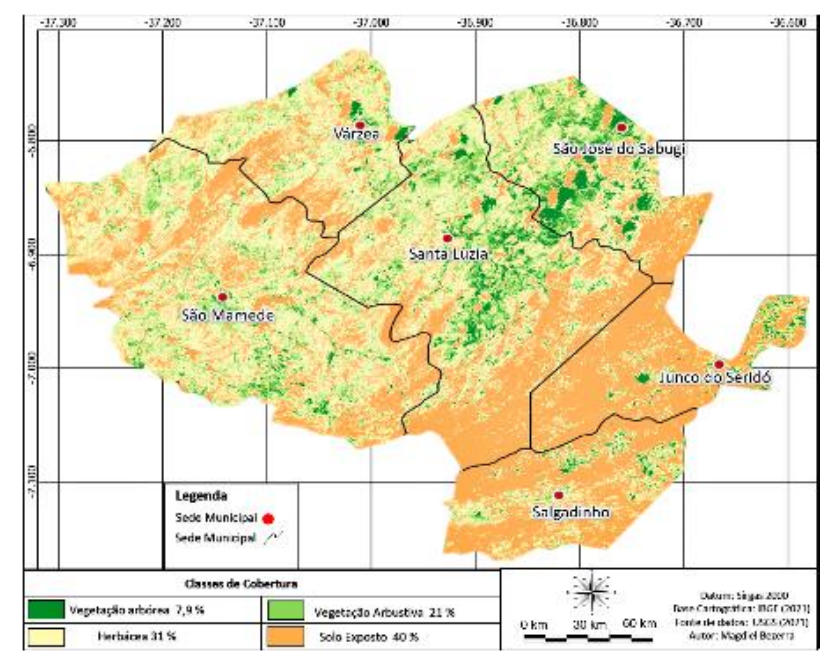

\begin{tabular}{|c|c|}
\hline \multicolumn{2}{|c|}{2008} \\
\hline Classes & Percentual \\
\hline Solo exposto & $40 \%$ \\
\hline Vegetação herbácea & $31 \%$ \\
\hline Vegetação arbustiva & $21,1 \%$ \\
\hline Vegetação arbórea & $7,9 \%$ \\
\hline Total & $100 \%$ \\
\hline
\end{tabular}

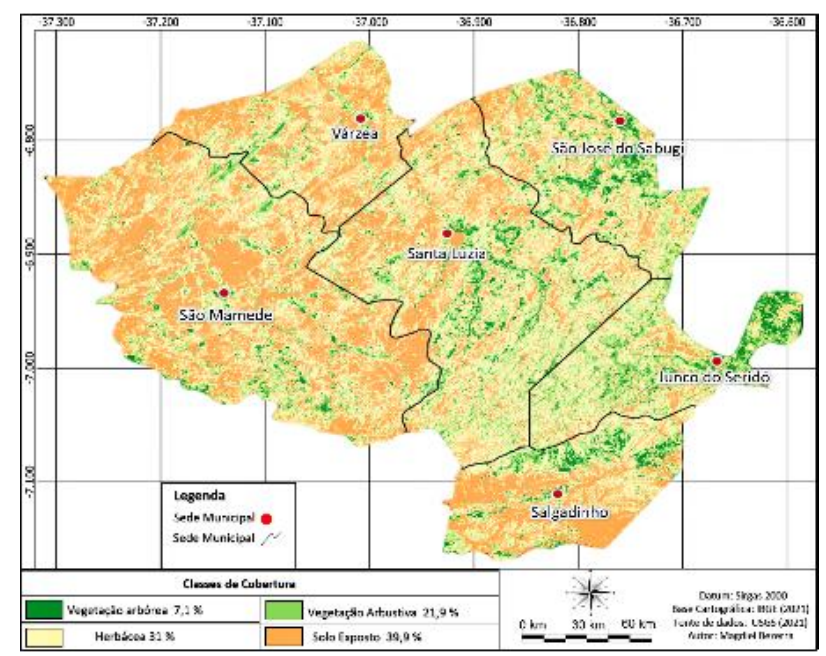

\begin{tabular}{|c|c|}
\hline \multicolumn{2}{|c|}{$\mathbf{2 0 0 9}$} \\
\hline Classes & Percentual \\
\hline Solo exposto & $39,9 \%$ \\
\hline Vegetação herbácea & $31 \%$ \\
\hline Vegetação arbustiva & $21,9 \%$ \\
\hline Vegetação arbórea & $7,2 \%$ \\
\hline Total & $\mathbf{1 0 0} \%$ \\
\hline
\end{tabular}




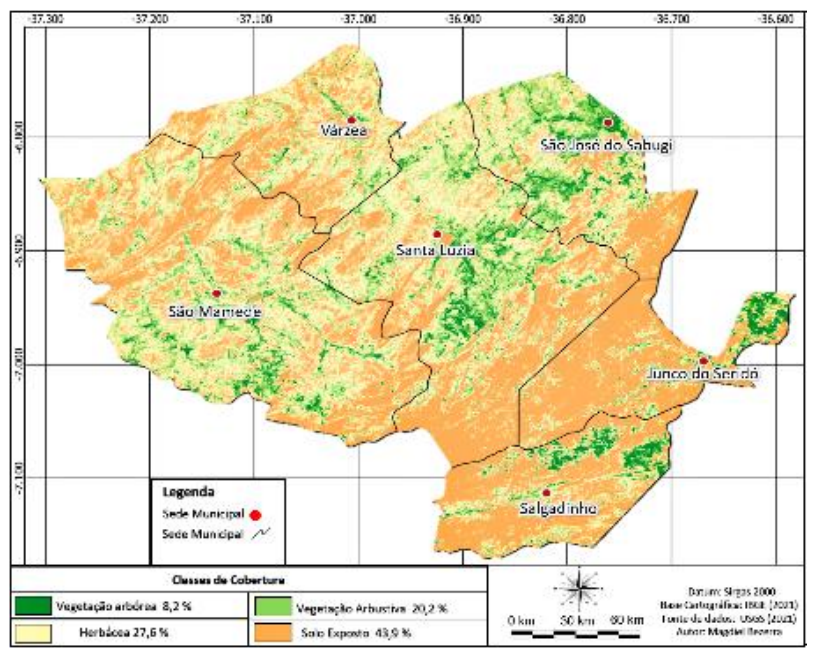

\begin{tabular}{|c|c|}
\hline \multicolumn{2}{|c|}{$\mathbf{2 0 2 0}$} \\
\hline Classes & Percentual \\
\hline Solo exposto & $43,9 \%$ \\
\hline Vegetação herbácea & $28 \%$ \\
\hline Vegetação arbustiva & $20,2 \%$ \\
\hline Vegetação arbórea & $7,9 \%$ \\
\hline Total & $\mathbf{1 0 0 \%}$ \\
\hline
\end{tabular}

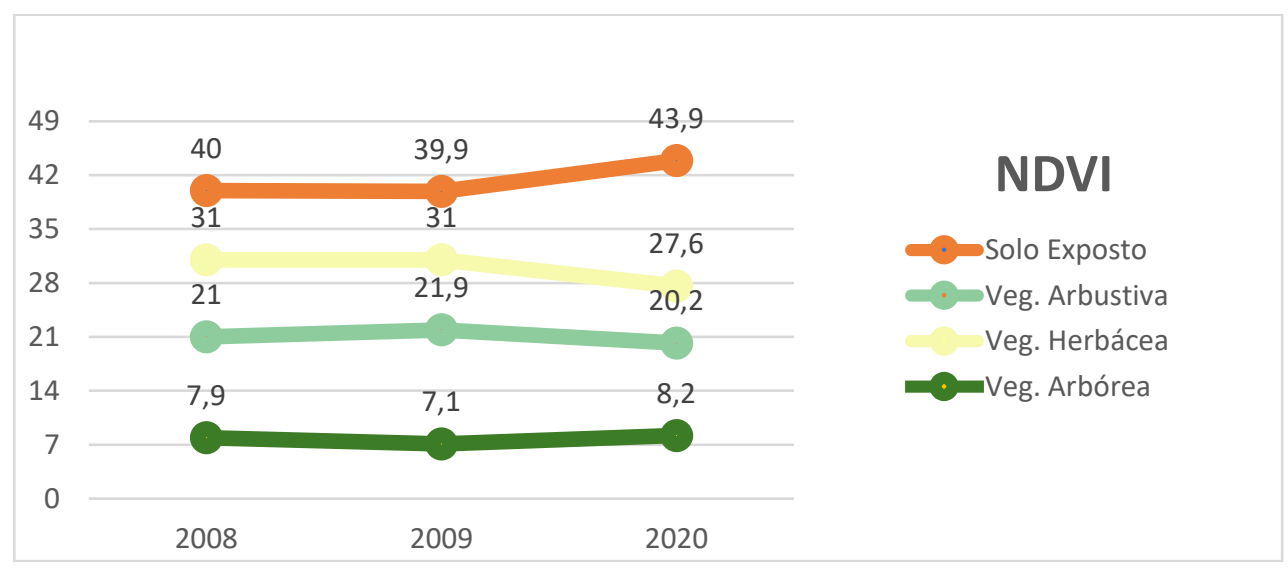

Fonte: Autores (2021).

Por meio da observação das imagens de NDVI, pode-se mapear a vegetação e medir as condições de solo exposto da área. Foram obtidos 3 (três) classes de cobertura vegetal: vegetação arbustiva, vegetação herbácea e vegetação arbórea. No ano de 2020 o percentual de vegetação arbustiva e herbácea mostrou-se em menor abrangência do que nos outros anos avaliados: 2008 e 2009. Como consequência o quantitativo de solo exposto em 2020 (43,9 \%) tornou-se maior que em 2008 (40 \%) e 2009 $(39,9 \%)$.

Essa situação fundamenta-se analisando em conjunto as médias pluviométricas da região, obtidos através do monitoramento da AESA (Figura 4), em que se observa que o ano de 2020 comportou-se como o mais seco entre os anos estudados: (2008 - 964,0 mm / 2009 - 901,3 mm / 2020 - 747,0 mm). 
Figura 4: Precipitação Média Microrregiões da Paraíba.

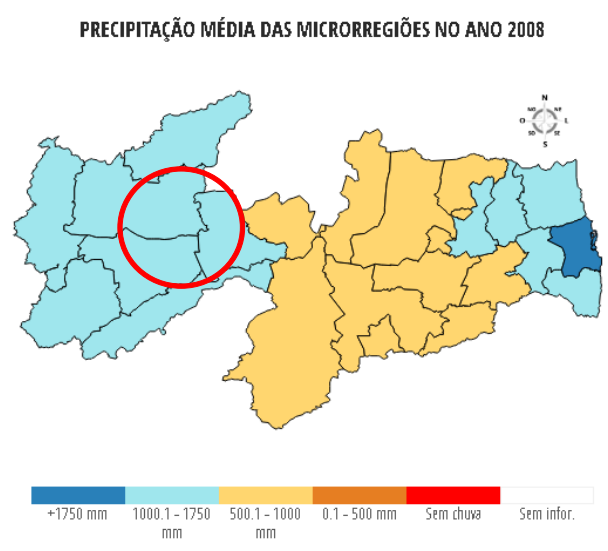

PRECIPITAÇÃO MÉDIA DAS MICRORREGIÕES NO ANO 2009
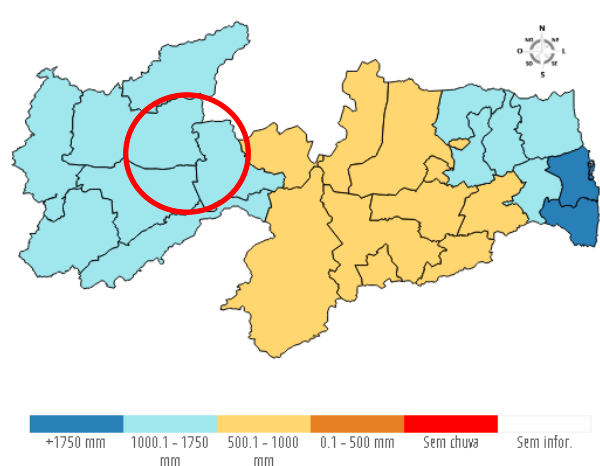

PRECIPITAÇÃO MÉDIA DAS MICRORREGIÕES NO ANO 2020

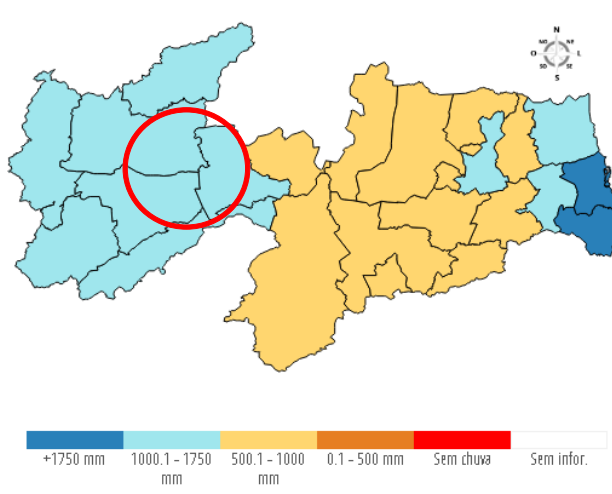

Fonte: AESA (2021).

Os indicativos do regime pluvial anual da região do Seridó Ocidental paraibano, associados as respectivas imagens do índice de vegetação da diferença normalizada, permitiram caracterizar as condições de vegetação do referido núcleo. Ao mesmo tempo pôde indicar que fatores climáticos adversos (baixas e irregulares precipitações) podem diminuir a camada vegetal na microrregião e gerar intensivos processos de degradação ambiental ou desertificação aliados principalmente a fatores antrópicos.

\section{Considerações Finais}

A caatinga é um bioma que sempre desempenhou grande importância histórica e econômica para a população do nordeste brasileiro e continua ocupando significante importância no cotidiano das famílias do Seridó Ocidental paraibano. Porém estudos mostram que a extração vegetal do Seridó Ocidental é destinada tanto para uso doméstico quanto para industrial (panificadoras, cerâmicas etc.), e não só para o consumo local, mas também para os estados vizinhos, principalmente Pernambuco.

A atividade econômica que predomina na atualidade é a mineração, embora a região tenha passado por outros ciclos econômicos ao longo dos anos, como a pecuária, agricultura e cotonicultura. Os danos ambientais resultantes de fatores antrópicos e climáticos tem causado grande pressão sobre os recursos naturais, e causado agressões que contribuem para o surgimento de núcleos de desertificação e infertilidade do solo.

O estudo aponta que os processos que levam a desertificação da microrregião estão ligados diretamente a fatores históricos predatórios de extração dos recursos naturais associados às condições naturais. Ao analisar a série histórica relacionada 
à extração de madeira para carvão e lenha nos municípios estudados, podemos verificar, apenas em Salgadinho houve decréscimo entre os anos de 2008 e 2018, embora esse município possua mais habitantes residindo na área rural do que urbana.

São Mamede e Junco do Seridó foram os municípios onde o índice de extração vegetal de madeira atingiram os maiores índices, principalmente nos últimos anos da pesquisa, entre 2017 e 2018. Os dados das médias pluviométricas mostram que a microrregião possui pluviosidade irregular, ocasionando longos períodos secos, que podem agravar o comportamento evolutivo dos níveis de erosão da microrregião e que os anos mais secos ocorreram entre 2012 e 2013.

O desmatamento continua sendo a principal causa dos elevados índices de degradação ambiental na microrregião, e mesmo existindo vastos trabalhos acadêmicos que contribuem com informações sobre o grau atual do problema, ainda não se percebe atitudes governamentais que adotem medidas para amenizar o quadro atual.

Faz-se necessário que políticas públicas sejam implantadas para potencializar programas que desenvolvam melhores condições de vida a população e que sejam capazes de implementar técnicas sustentáveis de manejo dos recursos naturais, respeitando as particularidades da região e utilizando técnicas que garantam a geração de renda e qualidade de vida.

Recomenda-se que para trabalhos futuros, sejam realizados estudos sobre o desmatamento aprofundados na região estudada em períodos mais atuais. Para além disso, estudos que identifiquem as melhores técnicas de recuperação da área em análise, identificando as melhores formas para deter os processos erosivos observados nas regiões áreas estudadas.

\section{Referências}

Accioly, L. J. O. (2000) Degradação do Solo e Desertificação no Nordeste do Brasil. Boletim informativo da Sociedade Brasileira de Ciência do Solo, ViçosaMG, 25(1), 23-25.

Alvares, C.A., Stape, J. L., Sentelhas, P. C., Gonçalves, J. L. de M., \& Sparovek, G. (2014) Köppen's climate classification map for Brazil. Meteorologische Zeitschrift, 22(1), 711-28.

Barros, A. H. C., Araújo Filho, J. C. de, Silva., A. B. da, Santiago. \& G. A. C. F. (2012) Climatologia do Estado de Alagoas. Boletim de Pesquisa e Desenvolvimento. Embrapa Solos n. 211. Recife. 32.

Brasil. (2012) Ministério da Integração Nacional. Secretaria de Desenvolvimento Regional. Plano de Ação Integrada e Sustentável da Mesorregião do Seridó. Brasília, 176.

Chander, G. \& Markham, B. (2003) Revised Landsat-5 TM Radiometric Calibration Procedures and Postcalibration Dynamic Ranges. IEEE Transactions on Geoscience and Remote Sensing. 41(11), 2674-7.

EMATER - PB. (2021) Empresa de Assistência Técnica e Extensão Rural da Paraíba. http://www3.emater.pb.gov.br/sigater/gera_pluviometria_aesa.php .

Filho, Ernani Martins dos Santos., Silva, Paulo Sérgio Gomes. \& Moizinho, Waltebergue Honório (2009). Caracterização das microrregiões do Seridó Ocidental e Oriental da Paraíba. X EREG.

Francisco, P. R. M., Medeiros, R. M. \& Santos, D. (2018) Balanço hídrico climatológico para a capacidade de campo de 100 mm: Estado da Paraíba. Campina Grande: EDUFCG, 257.

Freitas, Paulo Vitor Nascimento. (2013) O circuito inferior e o meio construído nas pequenas cidades do Seridó Ocidental paraibano. Monografia (TCC em Geografia) - Universidade Federal da Paraíba, 42.

Guerra, Antônio Teixeira Guerra \& Cunha, Sandra Baptista da. (1996) Geomorfologia e Meio Ambiente. Bertrand Brasil.

Instituto Brasileiro de Geografia e Estatística - IBGE (1990). Divisão regional do Brasil em mesorregiões e microrregiões geográficas (PDF). Biblioteca IBGE, $48-51$.

Instituto Brasileiro de Geografia e Estatística (IBGE) (2016). Divisão Territorial Brasileira.

Jacomine, P. K. T. Solos sob Caatinga: características e uso agrícola. (1996) In: Alvarez., V. H., Fontes., L. E. \& Fontes, M. P. F. O solo nos grandes domínios morfoclimáticos do Brasil e o desenvolvimento sustentado. SBCS, 95-133

Jacomine, P. K. T. \& Ribeiro, M. R., Montenegro, J. O. (1972) Levantamento exploratório reconhecimento de solos do Estado da Paraíba. (EPE-EPFS. Boletim Técnico, 15. SUDENE-DRN. Série Pedologia. Rio de Janeiro, 683.

Medeiros, J. A. B. (1980) Seridó. Brasília.

Ministério do Meio Ambiente. (2004) Biodiversidade da caatinga: áreas e ações prioritárias para a conservação. Brasília, Ministério do Meio Ambiente e Universidade Federal de Pernambuco. 
Research, Society and Development, v. 11, n. 3, e1411326082, 2022

(CC BY 4.0) | ISSN 2525-3409 | DOI: http://dx.doi.org/10.33448/rsd-v11i3.26082

Ministério do Meio Ambiente. (2017) Relatório sobre a Caatinga por Sensoriamento Remoto entre 2009 e 2011. Brasília-DF. https://www.gov.br/mma/ptbr/noticias/noticia-acom-2017-01-2096.

NAÇÕES UNIDAS. (1997) Convenção das nações unidas de combate à desertificação nos países afetados por seca grave elou desertificação, particularmente na África. MMA.

Pereira. I. M. et al., (2002) Composição florística e análise fitossociológica do componente arbustivo-arbóreo de um remanescente florestal no Agreste Paraibano. Acta Botânica Brasílica, 357-69.

Vasconcelos Sobrinho, J. (1971) Núcleos de desertificação no polígono das secas - nota prévia. In: ICB - UFPE, 69-73.

Paraíba (2017). Secretaria de Infraestrutura, dos Recursos Hídricos e do Meio Ambiente. Atlas Geográfico da Paraíba 2017. https://paraiba.pb.gov.br/diretas/secretaria-de-infraestrutura-dos-recursos-hidricos-e-do-meio-ambiente/arquivos/atlas-pb-2017.pdf/view 